\title{
https://doi.org/10.46813/2021-131-003 \\ STATUS AND PROSPECTS IN STELLARATOR RESEARCH AT IPP KIPT
}

\author{
V.E. Moiseenko, Yu.V. Kovtun, I.E. Garkusha \\ Institute of Plasma Physics, National Science Center "Kharkov Institute of Physics and \\ Technology", Kharkiv, Ukraine \\ E-mail:moiseenko@kipt.kharkov.ua
}

\begin{abstract}
A review of works performed at the Stellarator Department of KIPT is presented. It includes radio frequency (RF) plasma start-up, RF wall conditioning, RF plasma heating and diagnostics improvements at Uragan stellarators, studies of discharges for wall conditioning at Wendelstein 7-X Helias and some theoretical studies on magnetic configurations and tritium breeding. The prospects for the studies are associated with deeper involvement in EUROfusion activities.
\end{abstract}

PACS: 52.55.Hc; 52.50.-b

\section{INTRODUCTION}

Investigations on plasma physics and controlled thermonuclear fusion has been carried out at the Institute of Plasma Physics (IPP) of the National Science Center "Kharkov Institute of Physics and Technology" (NSC KIPT) for many years. One of the traditional directions in IPP research is investigations on plasma confinement within toroidal magnetic traps of a stellarator-type device. There are two stellarator type "torsatron" devices at the IPP. The bigger one is the Uragan-2M (U-2M) facility and the smaller Uragan-3M (U-3M). Since 2017 IPP is involved in the EURATOM fusion programme EUROfusion (European Consortium for the Development of Fusion Energy). The stellarator research at IPP KIPT is strongly determined by the integration of the studies to the EUROfusion Consortium activity within S1 work package. This paper summarizes recent experimental and theoretical results obtained on stellarator U-2M and U-3M devices in the last time.

\section{STUDIES AT URAGAN-2M}

\subsection{PLASMA START-UP}

In support of the ICRF experiments planned on the W7-X stellarator, that is, fast ion generation, wall conditioning, target plasma production and heating, a new two-strap antenna is recently installed at U-2M (Fig. 1) $[1,2]$. Its shape is similar to W-7X ICRH antenna and the main distinction is that it is just smaller. The main research tasks for the U-2M two-strap antenna (Figs. 2, 3) are the RF discharge plasma production (start-up) for further regular discharges, and plasma sustain in different RF vacuum chamber wall conditioning regimes.

A first experimental study on plasma production has been made in the U-2M stellarator using this antenna $[1,2]$.

The two-strap antenna consists of two parallel straps $60 \mathrm{~mm}$ wide and $600 \mathrm{~mm}$ long. The straps are made of
$2 \mathrm{~mm}$ thick stainless steel. The emitting parts of the straps are adjusted to the plasma edge. They are placed $10 \mathrm{~mm}$ distance from the last closed magnetic surface for U-2M magnetic configuration with $\kappa_{\varphi}=0.32$. The distance between the straps in toroidal direction is $250 \mathrm{~mm}$.

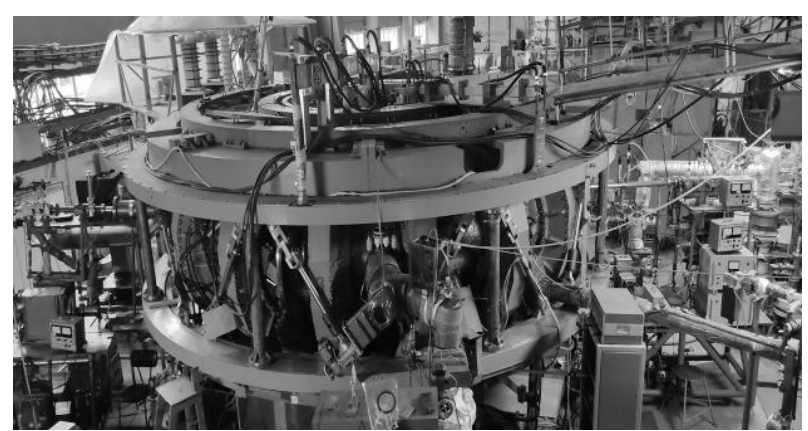

Fig. 1. General view of $U-2 M$

For all the experiments, antenna phasing is a monopole [1]. The W7-X-like antenna experiments with launched RF power of $\sim 100 \mathrm{~kW}$ have been performed in helium $\left(p=(4 \ldots 14) \cdot 10^{-2} \mathrm{~Pa}\right)$ with the vessel walls preloaded with hydrogen. Production of plasma with a density higher than $10^{11} \mathrm{~cm}^{-3}$ has been observed near the fundamental harmonic of the hydrogen cyclotron frequency. Operation at first hydrogen harmonic is feasible in W7-X future ICRF experiments. In experiments at U-2M, an ICRF plasma with an average density of $\sim(2 \ldots 2.6) \cdot 10^{12} \mathrm{~cm}^{-3}$ has been produced (Fig. 4). The discharges of such type have been described and the three stages of discharge development have been identified. The dependences of measured quantities on the discharge parameters have been analyzed. The dependence of the final average plasma density on the generator anode voltage (the launched power) saturates at high voltage values. Analysis of the OES data reveals that after the RF power launch, the $\mathrm{H}_{\Delta}$ line appears first, then the He I line after a small delay. The delay for He II and O II lines is quite long and becomes shorter with increasing RF power. The rate 
of plasma production is almost independent of the launched RF power at the initial plasma production stage and increases with power at further stages. The chord distribution of $\mathrm{He}$ I and $\mathrm{He}$ II lines luminosity are similar.

In the RF plasma production scenarios, RF generator operation without load is unavoidable. This happens at the initial stage of plasma production and could result in arcing. If the no-load stage is short, the probability of arcing is reduced to negligible values. In the scenario of plasma build-up studied, the no-load time is very small, $2 \ldots 3 \mathrm{~ms}$. A short plasma production time indicates that at all stages of plasma production the electrons are intensively heated by the RF field. The slow wave (SW) may play a key role in this. At the initial stage of plasma production, the direct SW excitation by the antenna comes into play. At higher plasma densities, the mode conversion minority scenario of electron heating is realized. The studied plasma production scenario looks promising and could possibly be used in machines larger than U-2M. The experiment for plasma production within such a scenario is planned at LHD stellarator at this year.
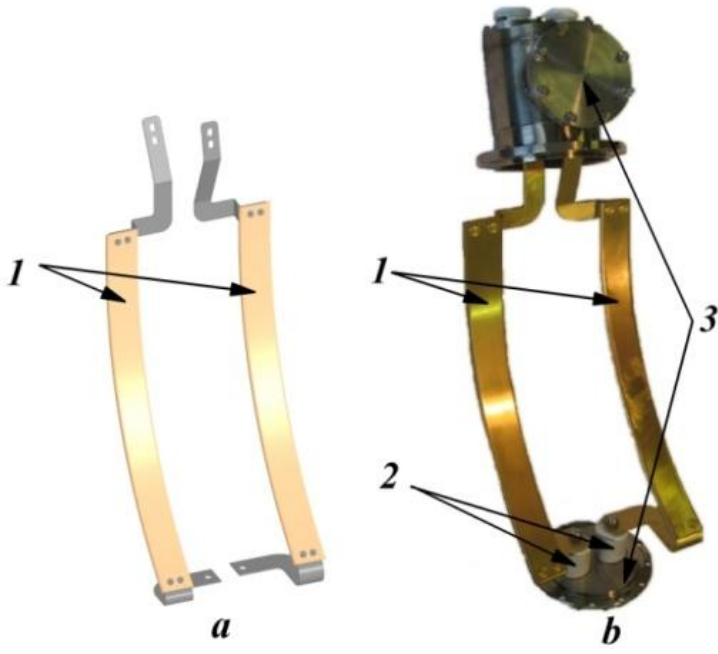

Fig. 2. Two-strap antenna:

Antenna model (a) and photo assembled with feedtroughs (b): 1 -straps; 2 -fluoroplastic isolators; 3 -elements of RF feed-troughs

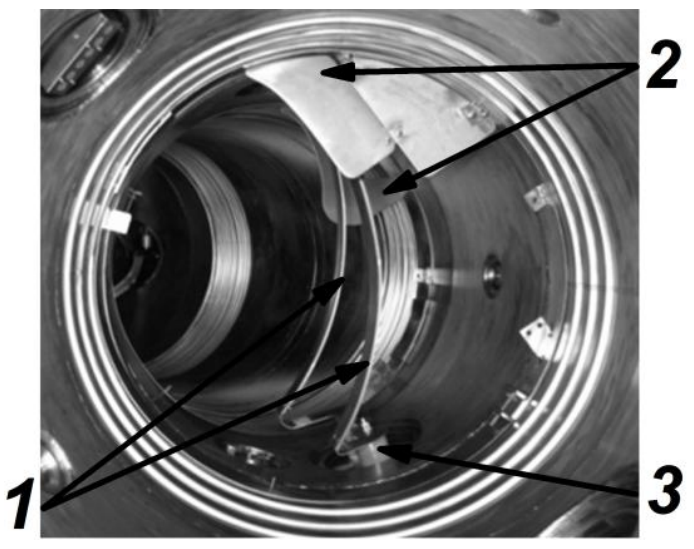

Fig. 3. Photo of the antenna inside the $U-2 M$ device: 1 -straps; 2 - limiters from both sides of antenna; 3 - fluoroplastic isolator covered with a quartz tube
The start-up experiments were carried out at stellarator with the Three-Half-Turn antenna (THT) without any pre-ionization [3]. Conditions for optimal gas breakdown were found out through the variation of the neutral gas pressure, magnetic field strength and anode voltage of RF generator. The optimum magnetic field was $0.37 \ldots 0.38 \mathrm{~T}$ while standard field was $0.4 \ldots 0.42 \mathrm{~T}$.

\subsection{WALL CONDITIONING WITH TWO-STRAP ANTENNA}

Decreasing the inflow of light and heavy impurities into the plasma column is of importance in hightemperature plasma experiments in frame of controlled fusion studies. This is the reason why an inner vacuum surface conditioning is the integral part of the functioning of fusion devices.
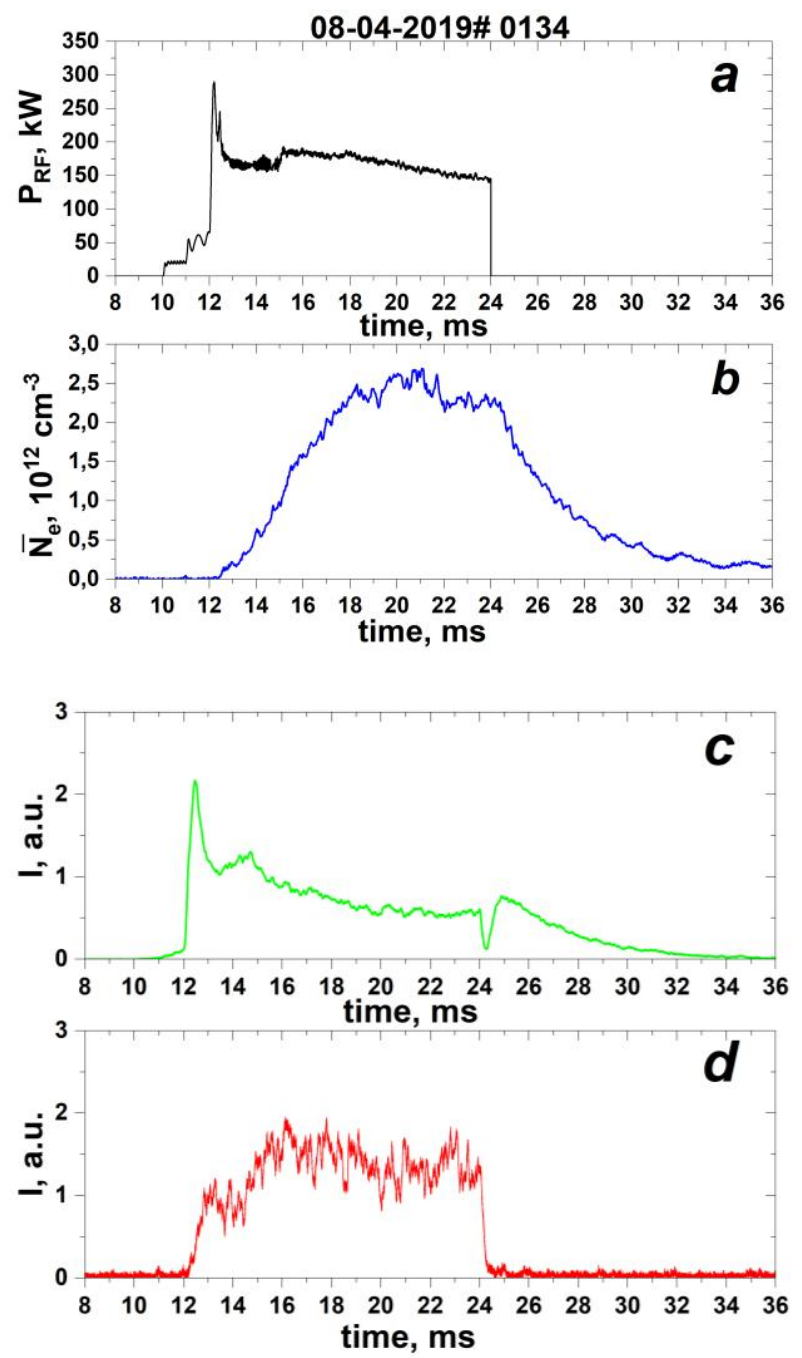

Fig. 4. Time evolutions of RF powers (a); average plasma density (b); optical emission intensities of He I, $447.15 \mathrm{~nm}(c)$; He II, $468.6 \mathrm{~nm}(d) ;\left(U_{a}=7.5 \mathrm{kV}\right)$ [1]

The wall conditioning in magnetic fusion devices is used after deconditioning events, such as leaks and opening the vacuum chamber to air and during the machine operational phase to remove impurities that migrate to the vacuum chamber from hidden places. 
The U-3M and U-2M vacuum chambers are RF conditioned in weak magnetic fields at frequencies up to $10 \mathrm{MHz}$. The frame and THT antenna were used for wall conditioning at $\mathrm{U}-2 \mathrm{M}$ in those experiments. The two-strap antenna operation is investigated in the vacuum chamber inner surfaces conditioning regime in a weak magnetic field in hydrogen atmosphere [2]. Plasma with the density $n_{\mathrm{e}} \sim(0.2 \ldots 0.95) \cdot 10^{12} \mathrm{~cm}^{-3}$ is successfully sustained. The RF frequency was $f \sim 5 \mathrm{MHz}$, $\mathrm{RF}$ plasma was sustained in stationery magnetic field $B_{0} \approx 0.01 \mathrm{~T}$, at hydroge pressure range $3 \cdot 10^{-3} \ldots 3 \cdot 10^{2} \mathrm{~Pa}$. The antenna matching device is tuned to optimum efficiency at plasma load conditions. The antenna - plasma coupling is high and compatible with that one in plasma heating regime. The RF discharge plasma can be sustained with only two-strap antenna during the whole impulse while the frame antenna is switched off.

\subsection{VHF WALL CONDITIONING}

The very high frequency (VHF) discharge for wall conditioning $\mathrm{U}-2 \mathrm{M}$ in nitrogen atmosphere is studied [4]. It is driven by the RF power at the frequency of 130 $\mathrm{MHz}$, higher than that usually used for ion cyclotron resonance heating. Nitrogen is chosen for its chemical activity and lower ability to penetrate into the wall material as compared with hydrogen. The wall conditioning is applied together with baking. This allows one to combine a decrease of the water amount in the vacuum chamber with an increase, due to high temperature, of the probability of chemical reactions of nitrogen atoms and ions with impurities accumulated at the plasma facing components. The volumetric VHF discharge is successfully ignited and stationary sustained, and plasma occupies most of the vacuum chamber volume. The probe measurements give the values of plasma density and electron temperature. The characteristic plasma densities are $(1.7 \ldots 4.2) \cdot 10^{15} \mathrm{~m}^{-3}$ and the electron temperature varies in the range of $8 \ldots 10 \mathrm{eV}$. This temperature is in consistency with the estimates made from optical measurements. The $\mathrm{N}_{2}, \mathrm{~N}_{2}{ }^{+}$ lines as well as the $\mathrm{CN}$ radical are observed in the optical emission spectrum of the plasma (Fig. 5). The formation of the $\mathrm{CN}$ radical is possible in various plasma chemical reactions with carbon-containing gas substances and also in the interactions of nitrogen with the impurities (carbon-containing) at the vacuum chamber surface. As a result of cleaning, the partial pressures of water, $\mathrm{N}_{2}+\mathrm{CO}, \mathrm{NH}_{3}$, and heavy hydrocarbons decrease by $52.9,38.6,87$, and $54.6 \%$ respectively (Fig. 6). The partial pressures of hydrogen, oxygen, argon, and $\mathrm{CO}_{2}$ respectively increase by 13.8 , $15.3,2.9$, and $14.3 \%$. These values are within the measurement error.

\subsection{DIAGNOSTICS AND LIMITER}

The diagnostic complex with the cryogenic nitrogen trap [5] was created to monitor the gas composition in the stellarator U-2M chamber. The complex provides several gas sampling options: directly from the vacuum chamber, and released gas at the cryogenic trap chamber after the trap being heated. A new cryogenic trap with its own valves was developed to implement the second option.

A new variant of the movable $\mathrm{B}_{4} \mathrm{C}$-limiter has been designed, manufactured and installed in the U-2M [6]. The influence of the limiter position relative to the minor axis was investigated in the regime of plasma heating in pulsed RF discharge.

\subsection{TORSATRON WITH REVERSED TOROIDAL MAGNETIC FIELD}

In the paper [7], the numerical calculations of magnetic field properties of the $l=2, m=6$ heliotron with irregular helical coil pitch. A vertical magnetic field compensation scheme, elaborated for the operating $l=2, m=2$ torsatron $\mathrm{U}-2 \mathrm{M}$ with the additional toroidal magnetic field coils, has been applied to compensate the vertical magnetic field of the $l=2, m=6$ heliotron with doubled length L-section. The calculation results show that due to the defined relation between the ampereturns in the compensation and in the helical coils the developed $l=2, m=6$ heliotron magnetic system with irregular helical coil pitch can provide some increase of the nested magnetic surface volume.

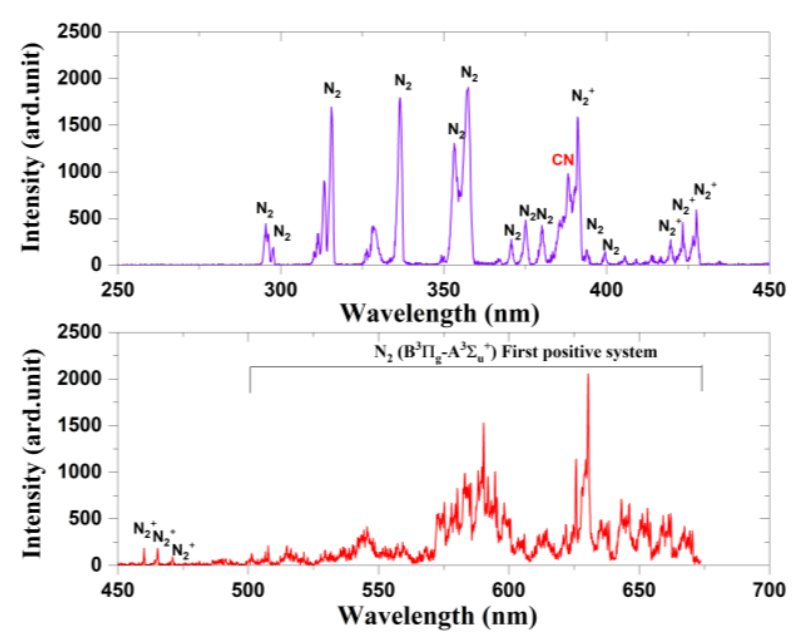

Fig. 5. Optical emission spectra of $\mathrm{N}_{2}$ plasma [4]

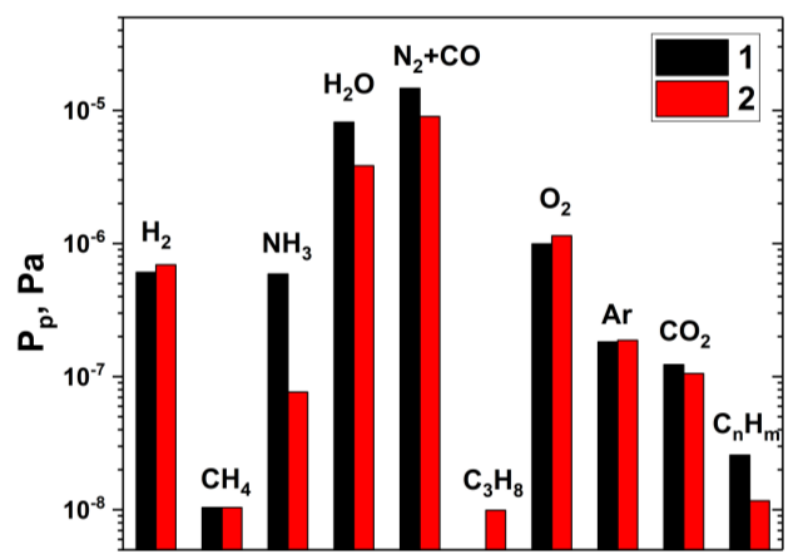

Fig. 6. Partial pressures of residual gas components: 1 - before baking and conditioning $\left(P_{\text {i.p. }}=4 \cdot 10^{-5} \mathrm{~Pa}\right)$ 18.01.2019; 2 - after baking and conditioning $\left(P_{\text {i.p. }}=1.7 \cdot 10^{-5} \mathrm{~Pa}\right)$ 25.01.2019 [4] 
Under normal operating conditions the toroidal field coils U-2M (16 toroidal magnetic field coils) create an additional toroidal magnetic field $\mathrm{B}_{0}$ the direction of which coincides with the direction of a toroidal magnetic field component $b_{0}$ generated by the torsatron helical coils on the circular axis of the torus. In the torsatron with reversed toroidal magnetic field (RTF) the toroidal field coils create an additional toroidal magnetic field $\mathrm{B}_{0 \mathrm{r}}$ of opposite direction. In the paper [8], the conditions for developing the magnetic surface configuration with spatial magnetic axis in the torsatron $\mathrm{U}-2 \mathrm{M}$ with RTF are found out and the magnetic surface configuration properties are investigated.

\section{URAGAN-3M}

The U-3M stellarator type torsatron device is the three-turn $(l=3)$ torsatron with nine periods $(m=9)$ of helical magnetic field (Fig. 7). The torus major radius is $R_{\text {tor }}=100 \mathrm{~cm}$, an average last-closed magnetic surface radius is $12 \mathrm{~cm}$ (average plasma minor radius) and the magnetic field ranges up to $1 \mathrm{~T}$.

\subsection{REGULAR DISCHARGES IN U-3M}

The U-3M device is equipped with two antennas which are fed by RF power with the frequency below ion cyclotron. The frame antenna was used for preionization and the THT antenna makes plasma heating. In experimental series, the radial profiles of $\mathrm{C} \mathrm{III,} \mathrm{O} \mathrm{V}$, and $\mathrm{C} \mathrm{V}$ optical line intensity and the second cyclotron harmonic emission are measured using a pulse-by-pulse technique [9]. The results of these measurements reveal existence of a small central area with relatively high electron temperature and good plasma confinement surrounded by a zone where the electron temperature and confinement are worse. The most plausible explanation is different rates of heat transport in these two zones. The outer zone dominates in volume and determines the global confinement characteristics such as the energy and particle confinement times that are below expected. The relatively high RF power needed to sustain plasma in this regime. The analysis of the U$3 \mathrm{M}$ standard magnetic configuration indicates that the system of nested magnetic surfaces exists only in the central zone. There are some options to change the configuration so that the area of the nested magnetic surfaces becomes wider. The inward-shifted magnetic configuration is a perspective choice in this respect.

\subsection{NEUTRAL PARTICLE ANALYZER, SOFT X-RAY DIAGNOSTICS AND FLUCTUATION SPECTRA}

The energy sweeping mode was used for the measurement of the energy distribution of charge exchange neutrals every $3 . .5 \mathrm{~ms}$ via a single-channel electrostatic neutral particle analyzer (NPA) in the U-3M [10]. The magnetic mass-separation (MS) part of NPA was omitted during these energy-sweeping measurements. The MS part is required for some experimental conditions in a case when different mass ions are present in plasma and for efficient suppression of parasitic influence of plasma radiation on the NPA measurements (due to geometrical factor).

Soft X-ray (SXR) diagnostics is routinely used in $\mathrm{U}-3 \mathrm{M}$. One of the SXR diagnostic applications is based on the plasma temperature estimation. The ratio of SXR signals passed through two different foils depends only on the plasma temperature and can be used for its estimation. An influence of spectral sensitivity of the photodiode on the two foils temperature estimations technique is considered numerically [11]. The influence is negligible in the case of the flat sensitivity in the energy range $5 \ldots .500 \mathrm{eV}$ in the case of thin $1.5 / 2.25 \mu \mathrm{m}$ Al foils.

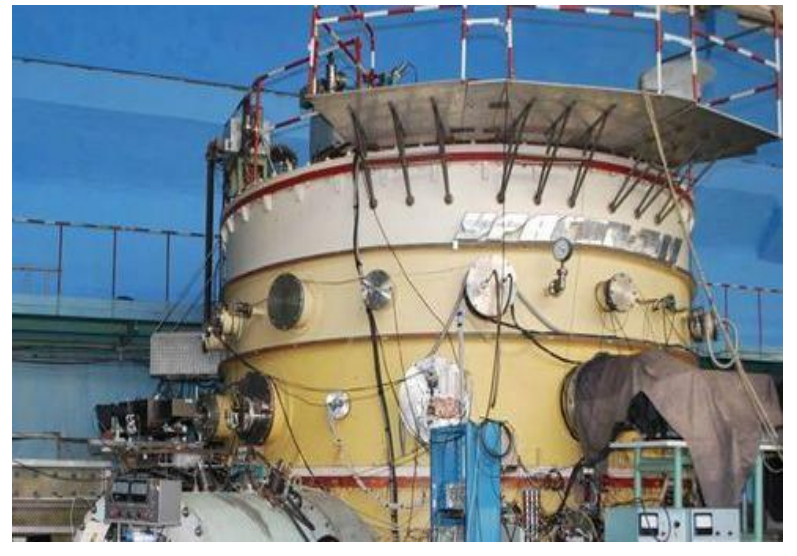

Fig. 7. Photo of $U-3 M$

Electromagnetic fluctuation spectra in the peripheral area of the U-3M trap and plasma density fluctuation spectra in the plasma confinement zone have been compared with the modulation spectra of runaway electron flux [12]. The dependence of the form of fluctuation spectra on the runaway electron flux intensity has been studied.

The magnetic field fluctuations were studied in weakly and strongly collisional plasmas U-3M [13]. Studies showed that the spectrum of the recorded magnetic field fluctuations consists of a relatively narrowband number of frequencies. The analysis indicates that the observed fluctuations of the magnetic field are a result of plasma instabilities, which cause perturbations of the plasma pressure.

\section{SCENARIO OF PULSED ECRH WALL CONDITIONING IN HYDROGEN FOR THE WENDELSTEIN 7-X (W7-X) HELIAS}

A scenario of short-pulse ECRH discharges series in hydrogen had been proposed for wall conditioning in W7-X [14]. In the beginning of the W7-X experimental campaign OP1.2b, successful discharges were produced in accordance to the proposed scenario, with a single and four ECRH pulses start-ups with use of a preionization plasma: A single ECRH pulse of $3 \mathrm{~ms}$ duration creates plasma of half density compared with preceding full-scale pulse ended $0.9 \mathrm{~s}$ before:

1. There are indications that the plasma is not fully ionized (optical lines behavior, half plasma density), 
and the atomic hydrogen intensive generation is expected.

2. Plasma decay is quite fast compared to the diffusion rate. It is rather recombination-like than diffusive. This allows one to use high repetition rate $(5 \mathrm{~Hz})$.

3. The H-alpha visible spectroscopy camera indicates volumetric plasma production during pulses;

4. The analysis of Balmer series of hydrogen optical lines point out the dissociation and recombination stages of the discharge.

5. A chain of 4 pulses accompanied with gas puff is successful. Such a chain may be a base for an ECWC scenario.

Thus, the feasibility of the proposed scenario implementation has been confirmed. A full elaboration of the optimal atomic hydrogen-based scenario for the wall conditioning using an ECRH in $\mathrm{W} 7-\mathrm{X}$ is planned.

\section{FUSION NEUTRON SOURCE}

\subsection{MAGNETIC FIELD SHAPING}

A mirror machine with a minimum B field for MHD stability is an option for a steady-state compact fusion neutron source design [15]. The ellipticity of flux surfaces at the perpendicular to magnetic axis crosssection increases with the mirror ratio, and magnetic shaping is made to find the minimal plasma column ellipticity at the mirror location. The ellipticity depends sensitively on the gyro center magnetic drift in the confinement region, and the optimal result approaches a state where the magnetic drift is made as small as possible, which corresponds to the SFLM (Straight Field Line Mirror) field. In such a magnetic field, in combination with a weak radial electric field, each guiding center is forced to move close to its mean magnetic surface, thereby suppressing neoclassical transport effects. Biased end plates, placed at the end tank outside the confinement region, is a tool to control the radial electric field and the positioning of drift surfaces in the confinement region. 3D superconducting coils have been computed which reproduce the magnetic field for a mirror ratio of 4. Mirror ratios exceeding 10 may be reachable with finite effects included. Analytical expressions in closed form are derived.

\subsection{TRITIUM BREEDING}

The paper [16] investigates producing tritium in sufficient quantities in the blanket of a fusion reactor (especially of a stellarator). In current blanket projects, tritium breeding ratio (TBR), the ratio of tritium production rate to the neutron production rate, is low (1.1...1.2). The MCNPX Monte-Carlo code has been used to model the neutron kinetics and to look for a principal possibility of increase TBR within a stellarator blanket limited space.

\section{CONCLUSIONS}

During last two year research in the Stellarator Department at KIPT continue to be more focused on stellarator-related problems. Key role in this plays involvement into EUROfusion activities, in particular in the Stellarator-1 work package. The experiments oriented on development scenarios for W7-X are started with the short-pulse ECRH wall conditioning (Section 3). The RF start-up studies with the two-strap antenna (Subsection 1.1) also are aimed to create a ground for W7-X X3 ECRH scenario. The low field wall conditioning will be proposed for W7-X too.

The future of the stellarator studies and experimental efforts at KIPT is imagined as more involved in EUROfusion activities accompanied with work on improving the local experimental base.

\section{ACKNOWLEDGEMENTS}

This work has been carried out within the framework of the EUROfusion Consortium and has received funding from the Euratom research and training programme 2014-2018 and 2019-2020 under grant agreement No. 633053. The views and opinions expressed herein do not necessarily reflect those of the European Commission.

The work was supported in part by the IAEA CRP F13019 and grants of the National Academy of Sciences of Ukraine A5-20 and P3-22.

\section{REFERENCES}

1. V.E. Moiseenko, Y.V. Kovtun, T. Wauters, et al. First experiments on ICRF discharge generation by a W7-X-like antenna in the Uragan-2M stellarator // Journal of Plasma Physics. 2020, v. 86, № 5, p. 905860517.

2. A.V. Lozin, Yu.V. Kovtun, V.E. Moiseenko, et al. // Two-strap RF antenna in URAGAN-2M stellarator // Problems of Atomic Science and Technology. Series «Plasma Physics». 2020, № 6, p.10-14.

3. V.E. Moiseenko, A.V. Lozin, M.M. Kozulia, et al. Three-half-turn antennas start-up // Problems of Atomic Science and Technology. Series «Plasma Physics». 2019, № 1, p. 263-266.

4. Y.V. Kovtun, V.E. Moiseenko, A.V. Lozin, et al. Characteristics of VHF discharge $\mathrm{N}_{2}$ plasma in Uragan2M stellarator // Acta Physica Polonica A. 2020, v. 138, № 4, p. 632-637.

5. S.A. Tsybenko, E.D. Kramskoj, V.B. Korovin, et al. Mass-spectrometer diagnostics complex with cryogenic nitrogen trap // Problems of Atomic Science and Technology. Series «Plasma Physics». 2019, № 1, p. 34-36.

6. G.P. Glazunov, A.V. Lozin, A.L. Konotopskiy, et al. Influence of movable $\mathrm{B}_{4} \mathrm{C}$-limiter on characteristics of $\mathrm{RF}$ discharge plasma in the Uragan-2M torsatron // Problems of Atomic Science and Technology. Series «Plasma Physics». 2019, № 1, p. 78-82.

7. V.G. Kotenko. Development of the $1=2, \quad m=6$ heliotron magnetic system with irregular helical coil 
pitch // Fusion Engineering and Design. 2020, v. 155, p. 111492.

8. V.G. Kotenko, R.O. Pavlichenko. Torsatron U-2M with reversed additional toroidal magnetic field // Problems of Atomic Science and Technology. Series «Plasma Physics». 2020, № 6, p. 15-18.

9. V.E. Moiseenko, A.N. Shapoval, A.V. Lozin, et al. Characteristics of regular discharges in Uragan-3M torsatron // Plasma Phys. Control. Fusion. 2019, v. 61, p. 065006.

10. M.B. Dreval, A.S. Slavnyj. Control system of neutral particle analyzer in energy sweeping mode // Fusion Engineering and Design. 2020, v. 151, p. 111412.

11. M.B. Dreval, O.V. Turianska, A.S. Pahur. Influence of the photodiode spectral sensitivity on the temperature estimation by SXR using thin filtering foils in Uragan3M // Problems of Atomic Science and Technology. Series «Plasma Physics». 2020, № 6, p. 19-21.

12. I.K. Tarasov, M.I. Tarasov, D.A. Sitnikov, et al. Escaping Electrons and Parametric Instability in the
Uragan-3M Torsatron // Technical Physics. 2020, v. 65, p. 354-361.

13. V.K. Pashnev, E.L. Sorokovoy, A.A. Petrushenya. Fluctuations of the Magnetic Field of Plasma Currents in Uragan-3M Stellarator // Plasma Physics Reports. 2020, v. 46, № 11, p. 1045-1058.

14. V.E. Moiseenko, A.A. Beletskii, A.M. Shapoval, et al. A scenario of pulsed ECRH wall conditioning in hydrogen for the Wendelstein 7-X helias // Problems of Atomic Science and Technology. Series «Plasma Physics». 2019, № 1, p. 37-40.

15. O. Ågren, V.E. Moiseenko. Magnetic shaping for a minimum B trap // Fusion Engineering and Design. 2020. v. 161, p. 111943.

16. S.V. Chernitskiy, V.E. Moiseenko. Tritium breeding calculation in a stellarator blanket // Problems of Atomic Science and Technology. Series «Plasma Physics». 2019, № 1, p. 49-52.

\section{СОСТОЯНИЕ И ПЕРСПЕКТИВЫ СТЕЛЛАРАТОРНЫХ ИССЛЕДОВАНИЙ В ИФП ХФТИ}

\section{В.Е. Моисеенко, Ю.В. Ковтун, И.Е. Гаркуиа}

Представлен обзор работ, выполненных в отделе стеллараторов ХФТИ, которые включают в себя: высокочастотное (ВЧ) создание плазмы, ВЧ-чистку стенок, ВЧ-нагрев и усовершенствования диагностик в стеллараторах Ураган, исследования разрядов для чистки стенок в гелиасе Wendelstein 7-X и некоторые теоретические исследования магнитных конфигураций и воспроизводства трития. Перспективы такого рода исследований связаны с более глубоким вовлечением в деятельность EUROfusion.

\section{СТАН І ПЕРСПЕКТИВИ СТЕЛАРАТОРНИХ ДОСЛІДЖЕНЬ В ІФП ХФТІ}

\section{В.С. Моісеєнко, Ю.В. Ковтун, І.С. Гаркуша}

Представлено огляд робіт, виконаних у відділі стелараторів ХФТІ, які включають в себе: високочастотне (ВЧ) створення плазми, ВЧ-чистку стінок, ВЧ-нагрівання і удосконалення діагностик у стелараторах Ураган, дослідження розрядів для очищення стінок у геліасі Wendelstein 7-X i деякі теоретичні дослідження магнітних конфігурацій і відтворення тритію. Перспективи такого роду досліджень пов'язані 3 більш глибоким залученням у діяльність EUROfusion. 